Copyright (C 2014 IEEE. Personal use of this material is permitted. Permission from IEEE must be obtained for all other uses, in any current or future media, including reprinting/republishing this material for advertising or promotional purposes, creating new collective works, for resale or redistribution to servers or lists, or reuse of any copyrighted component of this work in other works. 


\title{
Proposing a New Algorithm for Defining the Shortest Distance among ZigBee-Based Communication Devices in Microgrids
}

\author{
Made Andik Setiawan ${ }^{1,2}$, Farhad Shahnia ${ }^{2}$, Arindam Ghosh ${ }^{2}$, and Sumedha Rajakaruna ${ }^{2}$ \\ ${ }^{1}$ Politeknik Manufaktur Negeri Bangka Belitung, Sungailiat, Indonesia \\ ${ }^{2}$ Electrical and Computer Engineering Department, Curtin University, Perth, Australia \\ i.setiawan@postgrad.curtin.edu.au
}

\begin{abstract}
To improve the controllability within Future microgrids, a communication network needs to be available to provide data transfer within the MG. Wireless technologies such as ZigBee seem to be a good alternative for data transfer within MGs mainly due to low cost, more flexibility and acceptable data transfer rate. In such networks ZigBee-based repeaters are required to strengthen the communication signals if the DG units are scattered over a vast area. This paper mainly discusses on the algorithms required for defining the shortest distance between the DG units and the MG central controller. Different methods are discussed and a new algorithm is presented. Through the numerical analyses, it is demonstrated that the proposed method leads to a high reduction in the number of repeaters than other conventional algorithms.
\end{abstract}

Index Terms-Microgrid, Data Communication, Shortest Distance Algorithm, ZigBee.

\section{INTRODUCTION}

Microgrid (MG) is a cluster of loads, Distributed Generation (DG) units and energy storages interconnected by a network of feeders and located in the same geographical area. MG can act as an independent power system whenever needed [1]. For proper operation and control of the DG units within the MG, each DG should be updated instantly with the information about the MG operation status. This information is required to be transferred from the MG main circuit breaker to all DG units. Additionally, the MG central controller (MGC) requires the real-time measurement and reliable data exchange with grid, loads and DG units [2]. This includes fetching data from sensors within each DG unit or MG main circuit breaker. Then, the data needs to be transmitted to the local controllers (within DG units) or to the MGC. Later, the MGC commands need to be transferred to the actuators within the DG units and/or to the MG main circuit breaker. Therefore, automatic control and data communication technology is required for the MGs [1-3]. Fig. 1 shows schematically a MG with the power and communication networks.

Wired and wireless communication technologies may be employed for MG application. The wired technologies have higher data transfer bandwidth and are more reliable; however their installation cost is very high. On the other hand, the wireless technologies have less installation costs compared to the wired technologies and are more suitable for remote areas while being more flexible for the future expansions [4].

The popular wired technologies, used in power systems, are

This research was financially supported by Lembaga Pengelola Dana Pendidikan (LPDP), Ministry of Finance, Indonesia.

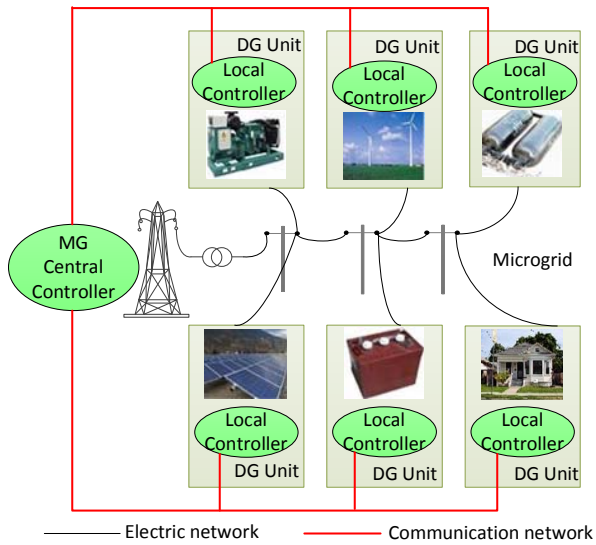

Fig. 1. Schematic diagram of a MG with communication network.

serial communication RS-232/422/485 [5], bus technology (e.g. ModBus, ProfiBus, CANBus) [6], power-line communication (e.g. DLC, PLC, BPLC) [3], and Ethernet (e.g. LAN, optical cable) [7]. On the other hand, the popular wireless technologies, used in power systems, are cellular (e.g. GSM, CDMA) [8], Wi-Fi [9], WiMax [10], ZigBee [11,12], Z-Wave [13], Bluetooth [14], Insteon [13], radio frequency [15] and Microwave [16].

The required communication technology in the MG application is to has a capability for covering the scattered location of the DG units, and handling numerous and massive number of the sensors/meters/actuators. However, establishing data communication infrastructure in the MG leads to a significant installation cost. For the MGs with DG units scattered over a larger geographical area, wired communication networks based on cables are very costly; hence, wireless communication systems are a better technique in such cases. These wireless systems need repeaters for improving the data transmission power and quality and for strengthening the wireless signal. Defining shorter distance for data communication in the MG is one of the most important issues need to be considered.

This paper develops and presents a new algorithm for defining shorter distance for wireless data communication in the future MGs.

\section{ShORTEST Distance AlgORIthm}

Djikstra and Bellman-Ford algorithms are two well-known algorithms for defining the shortest distance. These algorithms are usually used for finding the shortest route between two nodes in directed and weighted graph for data routing $[17,18]$. Both of Djikstra and Bellman-Ford algorithms are to find the 


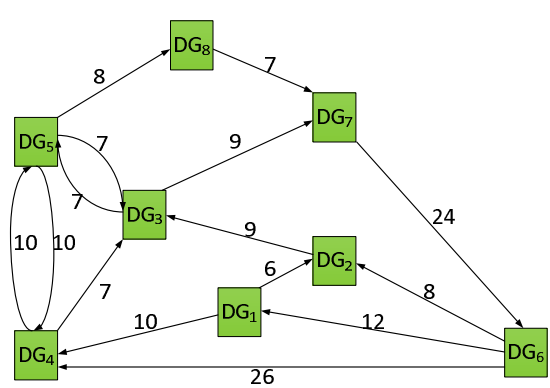

a) Weighted and directed graph

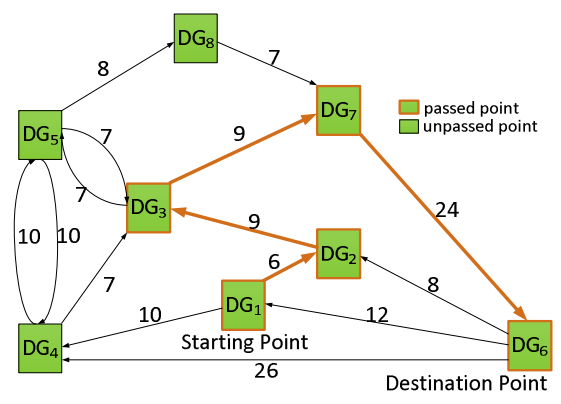

b) Djikstra algorithm

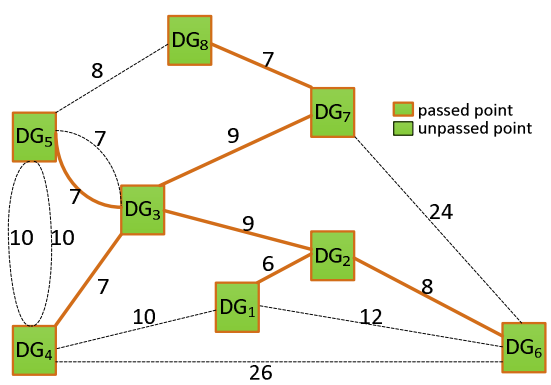

c) Required algorithm in MG communication

Fig. 2. Differences between weighted and directed graph, Djikstra algorithm and MG required algorithm.

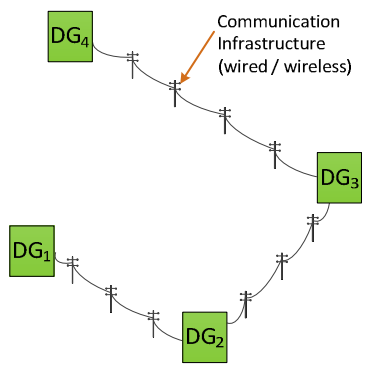

a) In the path of electric network

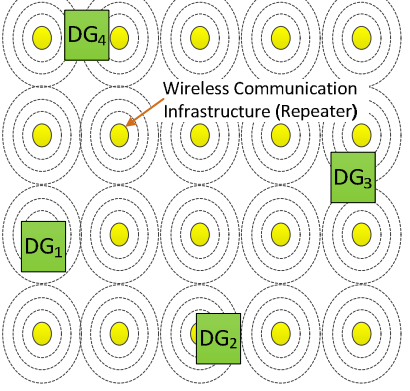

b) Square area

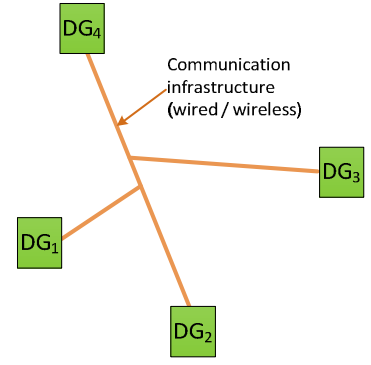

c) Point-to-point
Fig. 3. Three possible layouts of the communication infrastructure in a MG.

shortest route for transmitting data from the transmitter to the receiver. In addition, these algorithms can be applied while the graph has been weighted and routed. However, in MG application for new communication infrastructure, there is no weighted or routed graph. On the other hand, Djikstra and Bellman-Ford algorithms choose the minimum number of points to be passed, while in MG application all DG points must be connected. Table 1 shows the differences between Djikstra, Bellman-Ford algorithms and the requirements in MG applications.

Let us consider a MG with $i=8$ DGs to be connected in single communication network, and they are called $\mathrm{DG}_{1}, \mathrm{DG}_{2}$, etc. Each DGs has connection with other DGs in certain direction and value of the path. For an example, $\mathrm{DG}_{1}$ has ability sending data to $\mathrm{DG}_{2}$ and $\mathrm{DG}_{4}$ with 6 and 10 values respectively. In additional, $\mathrm{DG}_{1}$ can receive data from $\mathrm{DG}_{6}$ with 12 values. The values and direction of the path is used by Djikstra algorithm to define the shortest route for transmitting data. Fig. 2(b) shows the Djikstra shortest route for transmitting data from $D_{1}$ to $\mathrm{DG}_{6}$ is $\mathrm{DG}_{1}$ to $\mathrm{DG}_{2}, \mathrm{DG}_{2}$ to $\mathrm{DG}_{3}, \mathrm{DG}_{3}$ to $\mathrm{DG}_{7}$ and $\mathrm{DG}_{7}$ to $\mathrm{DG}_{6}$. This result indicates that the number connected DG is 5 instead of 8 DGs in total, and leaving 3 DGs unpassed.

However, for building the communication infrastructure in MG, all of DGs must be connected in single network without leaving any single unit DGs. This connection doesn't need the direction between two DGs, in additional, the value represents the distance and is still required to define the shortest distance. The shortest route in MG is defined by the smallest total distance connection to all DGs. In MG application, the shorter distance of communication infrastructure is preferred. Fig. 2(c) shows the required shortest distance algorithm for building $\mathrm{MG}$ communication infrastructure. In that figure, it can be shown that $\mathrm{DG}_{1}$ is connected to $\mathrm{DG}_{2}$ due to the distance between $D G_{1}$ to $D_{2}$ is shorter than $D_{1}$ to $D_{6}$ or $D G_{1}$ to $D_{4}$. This process is continued until all of DGs are connected.
Table 1. Differences between Djikstra and Bellman-Ford algorithm with the requirements in Microgrid

\begin{tabular}{|c|c|c|c|}
\hline & Djikstra's & Bellman-Ford & Microgrid \\
\hline Graph & Weighted & Weighted & $\begin{array}{l}\text { not established } \\
\text { yet }\end{array}$ \\
\hline Unit & Distance, cost, time & $\begin{array}{l}\text { Distance, cost, } \\
\text { time }\end{array}$ & Distance \\
\hline Value & Positive & $\begin{array}{l}\text { Positive and } \\
\text { negative }\end{array}$ & Positive \\
\hline $\begin{array}{c}\text { Passed } \\
\text { Point }\end{array}$ & Selected points & Selected points & All points \\
\hline Direction & Directed & Directed & Undirected \\
\hline $\begin{array}{l}\text { Source } \\
\text { point }\end{array}$ & $\begin{array}{l}\text { Starting and desti- } \\
\text { nation }\end{array}$ & Starting & $\begin{array}{l}\text { There is no } \\
\text { source point }\end{array}$ \\
\hline
\end{tabular}

The communication infrastructure in MG can be deployed in the following methods:

a) In the path of electric distribution network, as shown in Fig. 3(a). This method is easier for installation, maintenance and repair; however, the communication infrastructure distance can be long. This method is more suitable for crowded areas or for the established electricity facilities.

b) Squared area, as shown in Fig. 3(b). In this method, all of the area in which the MG is expanded will be covered by wireless (repeater) signals. This design is suitable to be applied in wind or photovoltaic farms which enormous sensors, meters or actuators are required to be monitored and controlled.

c) Point-to-point connection, as shown in Fig. 3(c). This method requires a mathematical calculation to define the shortest distance between any two points. This method will lead to the shortest distance and is more appropriate for new installation of communication infrastructure.

In the rest of the paper, the point-to-point method is further discussed in different approaches: 

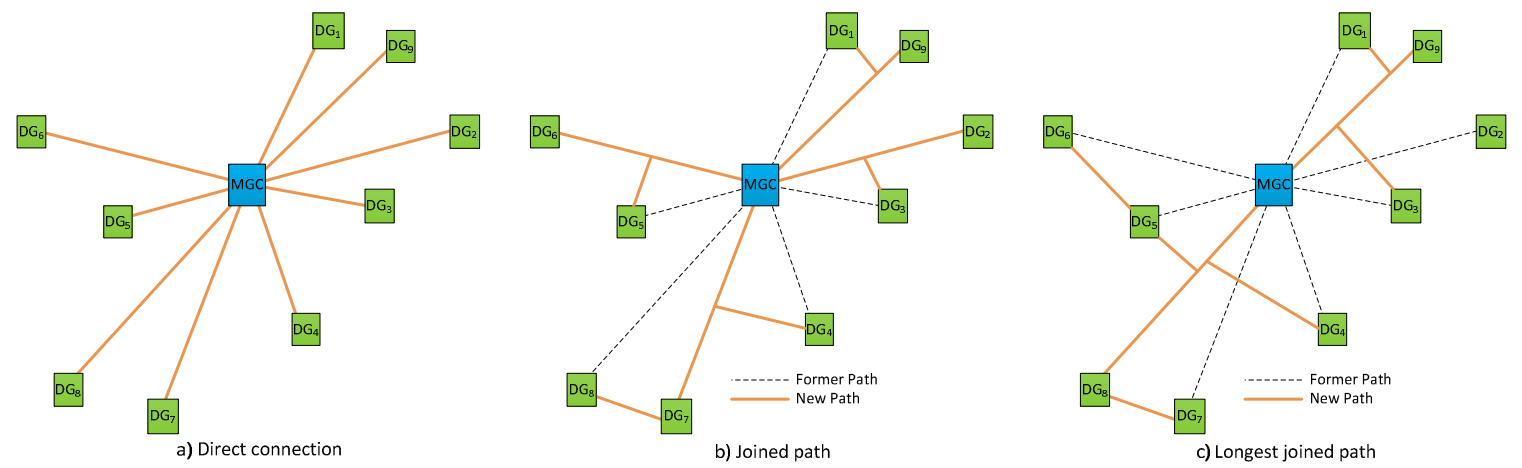

Fig. 4. Different point-to-point connection method in a MG.

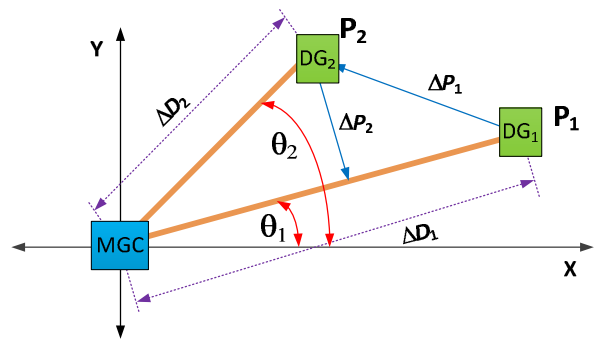

Fig. 5. Parameters in the joint path approach.

\section{A. Direct Connection Approach}

In this approach, the DGs controller is connected directly to the MG controller, as shown in Fig 4(a). In case the MG controller location has not been assigned initially, the algorithm can then define the location such that it is in the shortest possible distance to all DGs. This method may lead to the longest communication infrastructure in the MG.

\section{B. Joined Path Approach}

In this approach, the main idea is utilizing the direct connection approach but eliminating some of the paths, if one DG controller can be connected to the MG controller through the other DG communication infrastructure. For this, some possible paths can be joined together to form one common path. These joining paths have shorter distance in total. This approach is illustrated in Fig. 4(b).

For this, let us assume the location of the DG controller of each DG, based on Cartesian coordinate, as $(x, y)$. Then, the step-by-step procedure to define the desired path is as follows:

1. Calculating the distance between the DG controller of each

DG and the MG controller from

$$
\begin{aligned}
& \Delta D_{1}=\sqrt{\left(y_{1}-y_{c}\right)^{2}+\left(x_{1}-x_{c}\right)^{2}} \\
& \Delta D_{2}=\sqrt{\left(y_{2}-y_{c}\right)^{2}+\left(x_{2}-x_{c}\right)^{2}}
\end{aligned}
$$

2. Finding the closest short path. Assuming two DG controllers are located in $\left(x_{1}, y_{1}\right)$ and $\left(x_{2}, y_{2}\right)$, and the MG controller (MGC) location is $\left(x_{c}, y_{c}\right)$, as shown in Fig. 5 , the closest path can be defined from the angle deviation $(\Delta \theta)$ as

$$
\begin{aligned}
& \tan \theta_{1}=\frac{y_{1}-y_{c}}{x_{1}-x_{c}} \text { and } \tan \theta_{2}=\frac{y_{2}-y_{c}}{x_{2}-x_{c}} \\
& \Delta \theta=\left|\theta_{2}-\theta_{1}\right|
\end{aligned}
$$

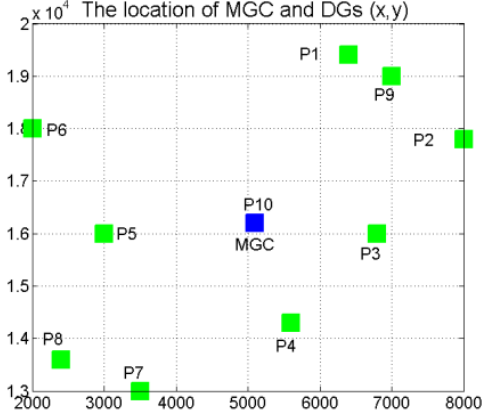

Fig. 6. The location of MGC and DGs

3. Joining the two adjacent paths. The shorter distance to $\mathrm{MG}$ controller $\left(\Delta D_{2}\right)$ is joined to the longer distance $\left(\Delta D_{1}\right)$.

4. DG controller $\mathrm{P}_{2}$ is only joined to controller $\mathrm{P}_{1}$ if the distance to new path $\left(\Delta P_{2}\right)$ is shorter than its former path $\left(\Delta D_{2}\right)$.

5. Repeating the steps 2 to 4 until all the adjacent paths are joined with other.

\section{Longest Joined Path Approach}

In this approach, for a group of DGs controller located in a close geographical area, first the longest distance between all DGs controller and the MGC is selected. Then, all other DGs controllers in that area are connected through shortest paths to that long connection line. Equations (1)-(4) are required to calculate the longest path and the shortest distances between each DGs controller and the selected long connection line. This is shown in Fig. 4(c).

\section{Shortest Distance Matrix Approach}

In this approach, a matrix is calculated which shows the distance between every two DGs controller in the MG. Then, each DGs controller is connected to the DGs controller which has the shortest distance among all of them. This approach requires the calculation of point-to-point distance in the form of a matrix.

Now, let us consider a MG with $i=10$ DG controllers. The DG locations based on Cartesian coordinate are given in $(x, y)$. As an example, $D_{1}$ till $D_{10}$ are called $P_{1}$ till $P_{10}$ respectively and located at $(6400,19400),(8000,17800),(6800,16000)$, $(5600,14300),(3000,16000),(2000,18000),(3500,13000)$, $(2400,13600),(7000,19000)$ and $(5100,16200)$. The spreading location of DGs is illustrated in Fig. 6.The distance matrix $(M)$ for this $\mathrm{MG}$ is given as 


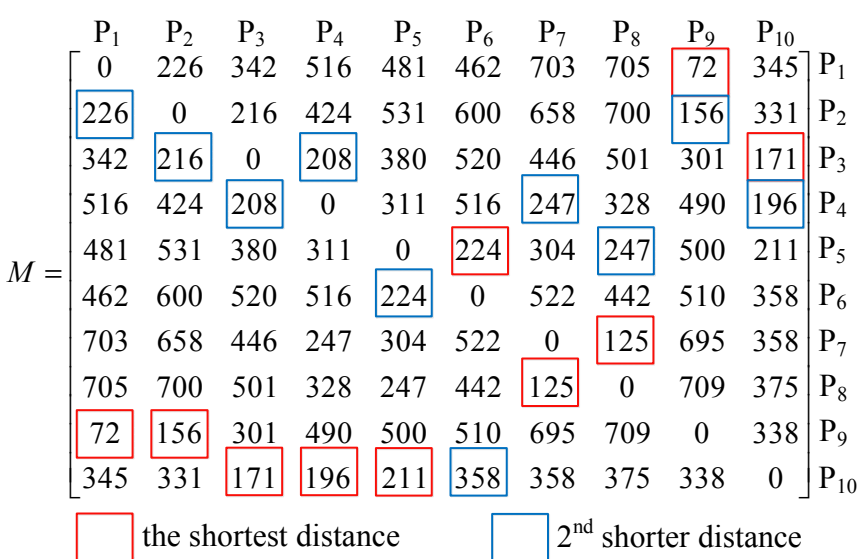

In the distance matrix, the shortest path between every two points is defined. These points are then connected together, for example, $\mathrm{P}_{1}$ is connected to $\mathrm{P}_{9}, \mathrm{P}_{2}$ is connected to $\mathrm{P}_{9}, \mathrm{P}_{3}$ is connected to $\mathrm{P}_{10}$, etc. It is to be noted that, there is a chance that the algorithm results in some isolated networks, as shown in Fig. 7. To prevent that, the $2^{\text {nd }}$ shorter point is chosen. If the isolated networks still remain, then a variable renaming takes place. In this regard, first $\mathrm{P}_{1}$ is renamed as $\mathrm{M}_{1}$. Then, the closest DG controller to $P_{1}$ is renamed as $M_{2}$. Next, the closest DG controller to $\mathrm{M}_{2}$ is renamed as $\mathrm{M} 3$. Note that if $\mathrm{M}_{3}$ is been selected before, the second shorter distance DG controller will be selected. This process continues till all DGs controllers are renamed from $\mathrm{M}_{1}$ till $\mathrm{M}_{i}$. For the example given above, the variable renaming are conducted as $\mathrm{P}_{1}=\mathrm{M}_{1}, \mathrm{P}_{2}=\mathrm{M}_{3}, \mathrm{P}_{3}=\mathrm{M}_{4}$, $\mathrm{P}_{4}=\mathrm{M}_{6}, \quad \mathrm{P}_{5}=\mathrm{M}_{9}, \quad \mathrm{P}_{6}=\mathrm{M}_{10}, \quad \mathrm{P}_{7}=\mathrm{M}_{7}, \quad \mathrm{P}_{8}=\mathrm{M}_{8}, \quad \mathrm{P}_{9}=\mathrm{M}_{2}, \quad \mathrm{P}_{10}=\mathrm{M}_{5}$. Hence, the new distance matrix $\left(M^{\prime}\right)$ based on the new variable renames is as below.

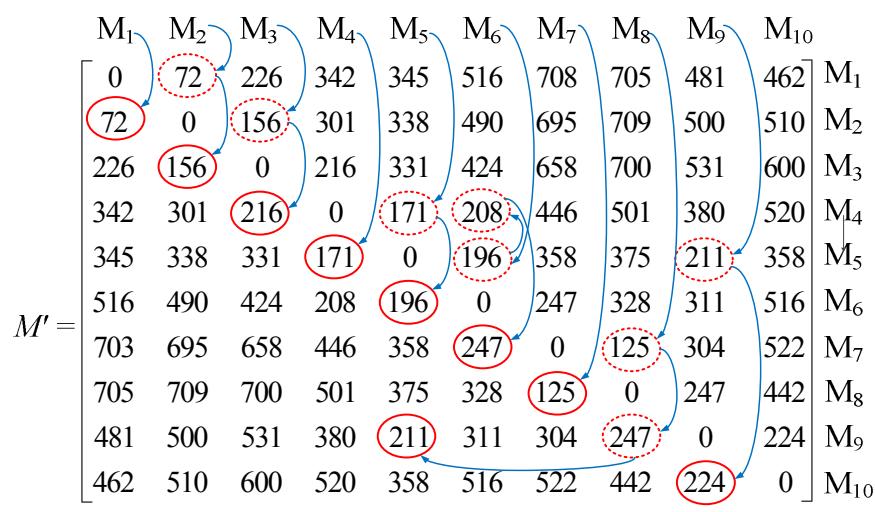

The process continues again starting from $\mathrm{M}_{1}$ and connecting it to the shortest point. For the selected DG controller, the shortest DG controller is again selected. If the shortest point is already selected, the second shorter DG controller is chosen. As an example, in the $M^{\prime}$ matrix given below, $\mathrm{M}_{1}$ is closest to $M_{2}, M_{2}$ is closest to $M_{1}$ but since it is been selected before, $M_{2}$ is connected to $\mathrm{M}_{3}$ which is the second shorter DG controller to $\mathrm{M}_{2}$. This is shown by the arrows over the $M^{\prime}$ matrix. The process continues until all DGs controllers are connected together. It is to be noted that if there is a closer DG controller to the second shorter DG controller in the same row of the $M^{\prime}$ matrix, then it will be connected to the closer DG controller and not the second shorter DG controller. The flowchart of this approach is shown in Fig. 8.

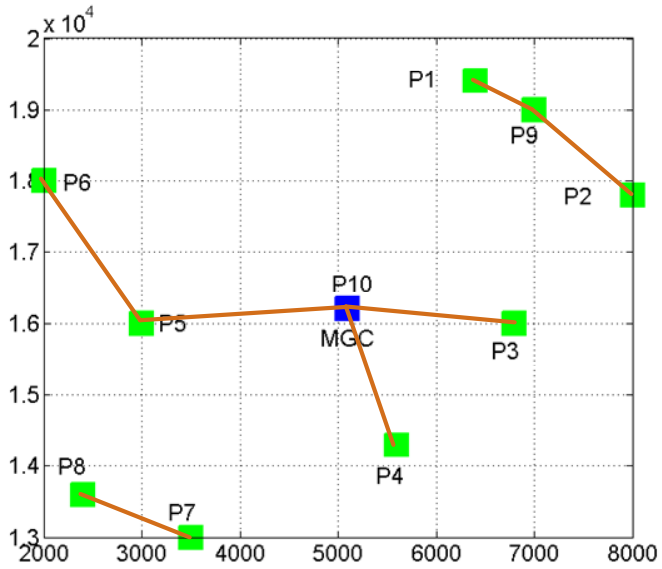

Fig. 7. Creation of three isolated networks as the result of using the only shortest distance in a MG.

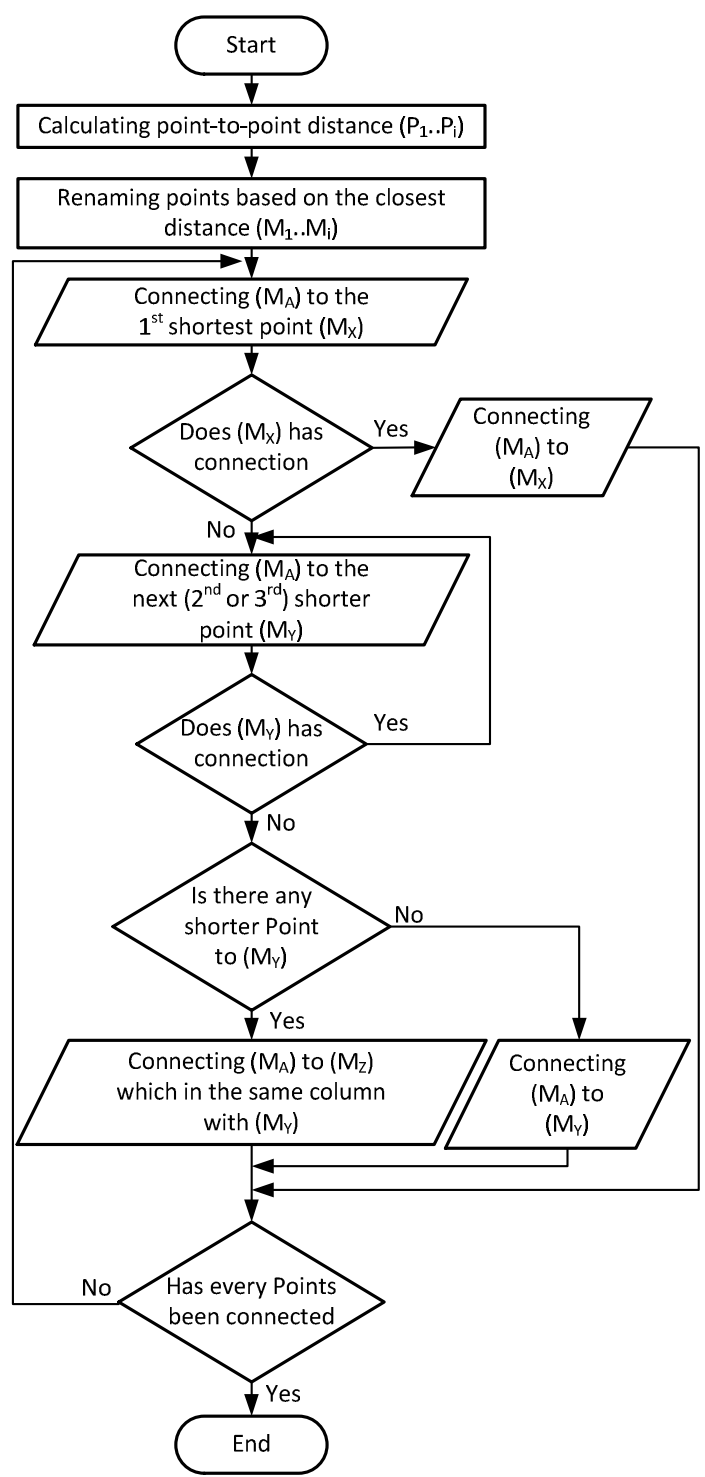

Fig. 8. Flowchart of the proposed shortest distance matrix approach.

\section{NuMERICAL RESUlts OF SHORTEST DistanCE}

The above discussed methods are modelled and numerically simulated in MATLAB for the MG example shown in Fig. 6 while the location of MG controller is assumed to be located at $(5100,1620)$ and $(4000,18000)$, while the DG locations are 

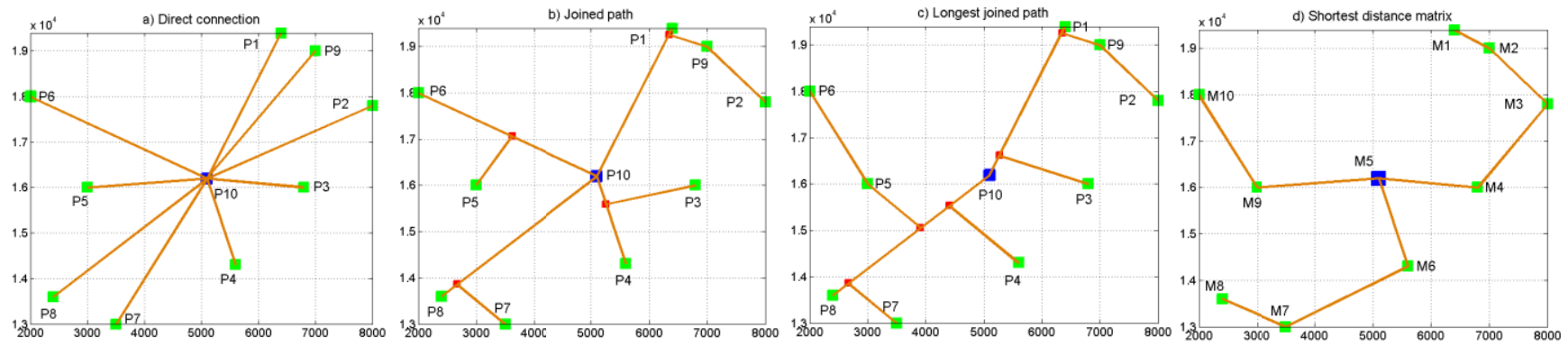

Fig. 9. Comparison between four different approaches for defining the communication network in MGs when MGC is located at (5100, 16200).
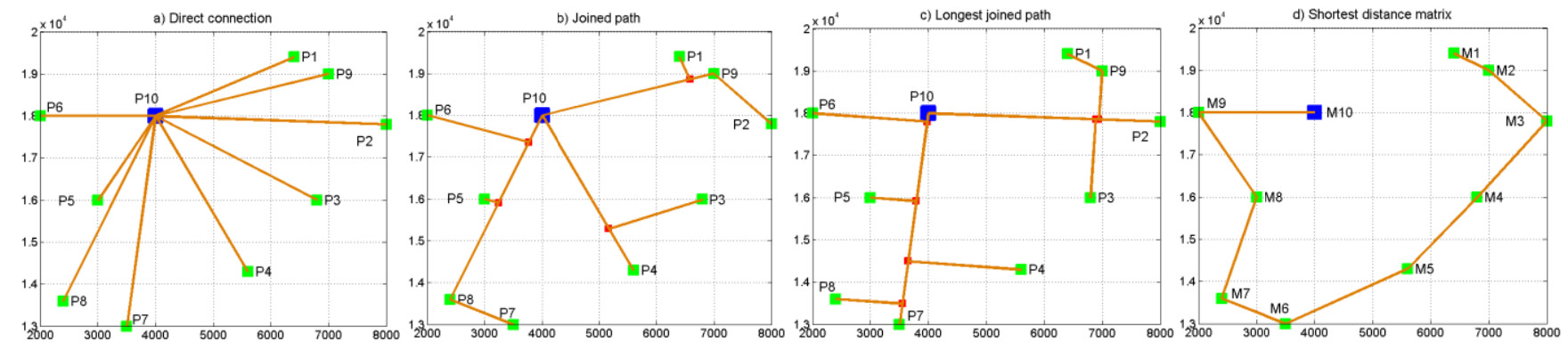

Fig. 10. Comparison between four different approaches for defining the communication network in MGs when MGC is located at (4000, 18000).
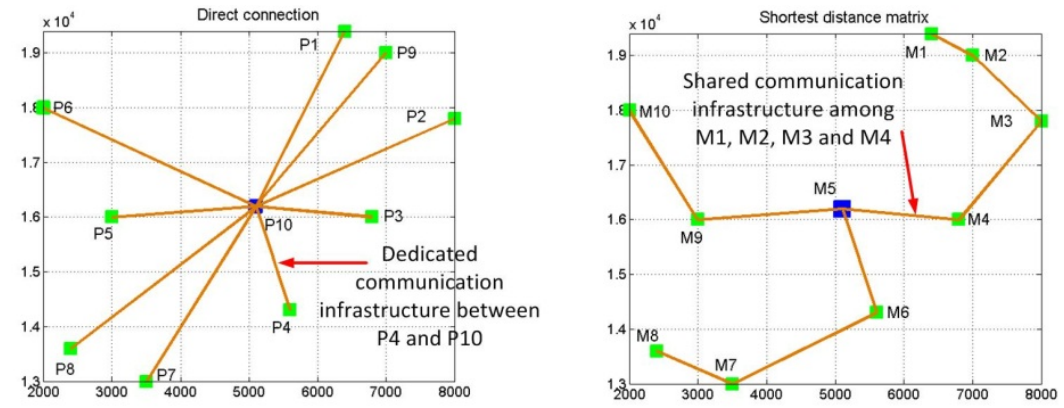

Fig. 11. Differences between dedicated with shared communication infrastructure in a MG.

assumed to be as shown on the figure. Fig. 9 and 10 show the results of defining the shortest distance between direct connection, joined path, longest joined path and shortest distance matrix approaches.

The total distance of communication infrastructure for direct connection approach in Fig. 9(a) is 26,846.51 m, however when applying the shortest distance matrix approach, the total distance is reduced to $16,191.29 \mathrm{~m}$.

In direct connection approach, all communication infrastructures from DG controller to MGC are dedicated for communication between each DG to MGC. However in shortest distance matrix approach, there are possibilities for sharing communication infrastructures among DGs. The shared communication infrastructure will propose the increasing of data latency in the MG [19]. Fig. 11 shows the differences between dedicated and shared communication infrastructure in MG.

\section{Data Latency For the Shortest Distance}

The data latency can be approximated by the time occupation ratio (TODR) which is the ratio of the time period which each DG controller can take to transmit data to the MG controller. The higher amount of TODR is correlated to the lower probability of data latency in the network. This TODR depends on the number of DG which shared the same communication infrastructure. Since the time allocated for each DG controller within the MG is equal, TODR is calculated from
$\operatorname{TODR}(\%)=\sum_{k=1}^{m} \frac{100}{N_{D G_{k}}^{l} \times N_{D G_{k}}^{l-1} \times \ldots \times N_{D G_{k}}^{l-m}}$

where $N_{D G_{k}}^{l}$ is the number of DGs which directly share communication infrastructure with $D G_{k}, N_{D G_{k}}^{l-1}$ is the number of DGs which directly share communication infrastructure with $D G_{l-1}$, where $D G_{l-1}$ is connected to and shares communication network with $D G_{l}$ and is defined as:

$N_{D G_{k}}^{l-j}=\left\{\begin{array}{ccc}2 & \text { if } & N_{D G_{k}}^{l-j-1} \neq 0 \\ 1 & \text { if } & N_{D G_{k}}^{l-j-1}=0\end{array}\right.$

According to (5), the total distance and the TODR of differences MGC location can be calculated. Table 2 shows the results of total distance and the TODR which the MGC location are defined in $(5100,16200),(3500,14500),(4000,18000)$, $(7000,15000),(6000,18000)$ and $(8000,12000)$. In these examples, the shortest distance is defined by shortest distance matrix approach which can reduce the total distance of communication infrastructure up to $65.7 \%$ than direct connection approach. While using longest joined path and joined path approach, the total distance can be decreased respectively up to $60.1 \%$ and $53.1 \%$. However, the TODR in shortest distance matrix approach is also decreasing while the distance is decr- 
Table 2. Summary of Simulating Four Different Approaches for Defining the Shortest Distance Communication Infrastructure in MGs.

\begin{tabular}{|c|c|c|c|c|c|c|c|c|c|c|c|}
\hline \multirow{3}{*}{$\frac{\operatorname{MGC}(x, y)}{(5100,16200)}$} & \multicolumn{2}{|c|}{ Direct connection } & \multicolumn{3}{|c|}{ Joined Path } & \multicolumn{3}{|c|}{ Longest Joined Path } & \multicolumn{3}{|c|}{ Shortest Matrix } \\
\hline & \multirow{2}{*}{$\begin{array}{c}\begin{array}{c}\text { Total } \\
\text { Distance }(\mathrm{m})\end{array} \\
26,846.51\end{array}$} & \multirow{2}{*}{$\begin{array}{c}\begin{array}{c}\text { TODR } \\
(\%)\end{array} \\
900\end{array}$} & \multicolumn{2}{|c|}{$\begin{array}{c}\text { Total } \\
\text { Distance }(m)\end{array}$} & \multirow{2}{*}{$\begin{array}{c}\begin{array}{c}\text { TODR } \\
(\%)\end{array} \\
400\end{array}$} & \multicolumn{2}{|c|}{$\begin{array}{c}\text { Total } \\
\text { Distance }(m)\end{array}$} & \multirow{2}{*}{$\begin{array}{c}\text { TODR } \\
(\%)\end{array}$} & \multicolumn{2}{|c|}{$\begin{array}{c}\text { Total } \\
\text { Distance }(\mathrm{m})\end{array}$} & \multirow{2}{*}{$\begin{array}{c}\begin{array}{c}\text { TODR } \\
(\%)\end{array} \\
300\end{array}$} \\
\hline & & & 19,036 & $-29.1 \%$ & & $17,580.34$ & $-34.5 \%$ & & $16,191.29$ & $-39.7 \%$ & \\
\hline$(3500,14500)$ & $31,019.76$ & 900 & 20,685 & $-33.3 \%$ & 400 & $17,562.18$ & $-43.4 \%$ & 300 & $15,128.33$ & $-51.2 \%$ & 301 \\
\hline$(4000,18000)$ & $31,360.71$ & 900 & 19,172 & $-38.9 \%$ & 300 & $18,657.86$ & $-40.5 \%$ & 200 & $16,960.1$ & $-45.9 \%$ & 100.971 \\
\hline$(7000,15000)$ & $32,792.5$ & 900 & 21,906 & $-33.2 \%$ & 400 & $17,275.88$ & $-47.3 \%$ & 101.2 & $15,464.29$ & $-52.8 \%$ & 177 \\
\hline$(6000,18000)$ & $29,636.62$ & 900 & 18,645 & $-37.1 \%$ & 300 & $17,952.49$ & $-39.4 \%$ & 150 & $16,365.05$ & $-44.8 \%$ & 202 \\
\hline$(8000,12000)$ & $53,264.61$ & 900 & 24,988 & $-53.1 \%$ & 97 & $21,273.7$ & $-60.1 \%$ & 102 & $18,284.26$ & $-65.7 \%$ & 152 \\
\hline Average & & 900 & & $-37.4 \%$ & 316 & & $-44.2 \%$ & 175.5 & & $-50.0 \%$ & 205.5 \\
\hline
\end{tabular}

eased. The average TODR using joined path, longest joined path and shortest distance matrix approach are respectively $316 \%, 175.5 \%$ and $205.5 \%$, instead of the maximum TODR is $900 \%$. These TODR values indicate that the probability of data latency by utilizing the joined path, longest joined path and shortest distance matrix approach increase up to $280 \%$, $520 \%$ and $440 \%$ respectively than the dedicated communication infrastructure between DGs and MGC.

\section{CONCLUSIONS}

To have a central control in a microgrid, data transfer is required between the distributed generation units and the central controller of the MG. However, establishing data communication infrastructure in the MG leads to a significant installation cost. Therefore, defining shorter distances for data communication in the MG is an important economic issue to be considered. Four different methods based on point-to-point connection strategy are discussed in this paper, including a new method. Using numerical analyses in Matlab, it is shown that the distance between the communication infrastructure for connecting all DGs and MGC is reduced by implementing the proposed method. However, the probability of data latency in the MG communication network may be increased by implementing these approaches. Hence, selecting a suitable approach can be defined using an optimization technique which considers the geographical area, data latency requirement, maximum installation cost limits, communication topology, number of DGs, etc. This can be a future research topic.

\section{REFERENCES}

[1] F. Shahnia, R.P.S. Chandrasena, S. Rajakaruna and A. Ghosh, "Primary control level of parallel DER converters in system of multiple interconnected autonomous microgrids within self-healing networks," IET Generation, Transmission and Distribution, vol. 8, no. 2, pp. 203222, 2014.

[2] N.K. C. Nair and L. Zhang, "SmartGrid: Future networks for New Zealand power systems incorporating distributed generation," Energy Policy, vol. 37, no. 9, pp. 3418-3427, Sep. 2009.

[3] E. Kabalci, Y. Kabalci, and I. Develi, "Modelling and analysis of a power line communication system with QPSK modem for renewable smart grids," Int. Journal Electr. Power Energy Syst., vol. 34, no. 1, pp. 19-28, Jan. 2012.
[4] X. Peng, X. Zou, Z. Yu, and Y. Yang, "Design of Household Appliance Control System Based on ZigBee," Cloud Computing and Intelligent Systems (CCIS), pp. 1067-1071, 2012.

[5] G. Heideck, M. Purmann, and Z. Styczynski, "Multi channel voltage control for fuel cells," Journal Power Sources, vol. 145, no. 2, pp. 594597, Aug. 2005.

[6] N. Goldenberg and A. Wool, "Accurate modeling of Modbus/TCP for intrusion detection in SCADA systems," Int. Journal Crit. Infrastruct. Prot., vol. 6, no. 2, pp. 63-75, Jun. 2013.

[7] C. Zhang, W. Ma, and C. Sun, "A switchable high-speed fiber-optic ring net topology and its method of high-performance synchronization for large-capacity power electronics system," Int. Journal Electr. Power Energy Syst., vol. 57, pp. 335-349, May 2014.

[8] N. Radhika and V. Vanitha, "Smart Grid Test Bed Based on GSM," Procedia Eng., vol. 30, no. 2011, pp. 258-265, Jan. 2012.

[9] A. Usman and S. H. Shami, "Evolution of Communication Technologies for Smart Grid applications," Renew. Sustain. Energy Rev., vol. 19, pp. 191-199, Mar. 2013

[10] A. Cama, F. G. Montoya, J. Gómez, J. L. De La Cruz, and F. ManzanoAgugliaro, "Integration of communication technologies in sensor networks to monitor the Amazon environment," J. Clean. Prod., vol. 59, pp. 32-42, Nov. 2013.

[11] N.C. Batista, R. Melício, J.C.O. Matias, and J.P.S. Catalão, "Photovoltaic and wind energy systems monitoring and building/home energy management using ZigBee devices within a smart grid," Energy, vol. 49, pp. 306-315, Jan. 2013.

[12] N.K. Suryadevara, S. Member, S.C. Mukhopadhyay, et al., "WSN-Based Smart Sensors and Actuator for Power Management in Intelligent Buildings," IEEE/ASME Trans. Mechatronics, vol. PP, no. 99, pp. 1-8, 2014.

[13] S. Ahmad, "Smart metering and home automation solutions for the next decade," International Conference on Emerging Trends in Networks and Computer Communications (ETNCC), pp. 200-204, 2011.

[14] N. Sahu and V. Dehalwar, "Intelligent Machine to machine communication in Home area network for Smart grid," Computing Communication \& Networking Technologies (ICCCNT), pp. 1-6, 2012.

[15] N. Kilic and V.C. Gungor, "Analysis of low power wireless links in smart grid environments," Comput. Networks, vol. 57, no. 5, pp. 11921203, Apr. 2013.

[16] C. Deng, X. Xiao, Z. Fu, G. Liu, H. Yang, and J. Liu, "TerrestrialSatellite Hybrid Backbone Communication Network for Smart Power Grid," Energy Procedia, vol. 12, pp. 27-36, Jan. 2011.

[17] J. Singh, P. Veeraraghavan, and S. Singh, "QoS multicast routing using Explore Best Path," Comput. Commun., vol. 29, no. 15, pp. 2881-2894, Sep. 2006.

[18] C. W. Duin, "Two fast algorithms for all-pairs shortest paths," Comput. Oper. Res., vol. 34, no. 9, pp. 2824-2839, Sep. 2007.

[19] W. Stallings, Data and Computer Communication : Eight edition, New Jersey: Pearson Prentice Hall, 2007. 